\title{
Indução de resistência à Mosca minadora em crisântemo usando com- posto silicatado
}

\author{
Ricardo Antônio Polanczyk; Dirceu Pratissoli; Henrique de Sá Paye; Victor A Pereira; Fabíola LS Barros; \\ Regina GS Oliveira; Renato R Passos; Sebastião Martins Filho \\ CCA/UFES, Alto Universitário s/n, 29500-000 Alegre-ES; pratissoli@cca.ufes.br
}

\section{RESUMO}

Avaliou-se o uso de um composto silicatado (escória siderúrgica) como forma de induzir a resistência ao ataque da mosca minadora (Liriomyza spp) em duas cultivares de crisântemo. A pesquisa foi desenvolvida na empresa Tristão Flores, Iúna (ES), sob estufas plásticas. Os tratamentos foram dispostos no delineamento inteiramente casualizado, em um esquema de parcelas subsubdivididas, com cinco repetições, sendo alocadas nas parcelas duas cultivares de crisântemo (Polar Branco e Polar Amarelo), nas subparcelas cinco doses de escória siderúrgica $(0 ; 1,40 ; 2,80 ; 4,20$ e 5,60 g por vaso) e na subsubparcela as semanas. Avaliaram-se as larvas vivas de mosca minadora e o número de folhas minadas, semanalmente, por um período de nove semanas. Os resultados mostram a potencialidade do uso de escória siderúrgica no controle da mosca minadora. A cultivar Polar Branco apresentou menor suscetibilidade ao ataque de mosca minadora, com o menor número de folhas minadas e menor número de larvas vivas.

Palavras-chave: Liriomyza spp., Dendranthema grandiflorum Tzvelev, inseto-praga, manejo.

\begin{abstract}
Silicate compost used as resistance inductor against the leafminer on chrysanthemum

The silicate compost (basic slag from metallurgy) use was evaluated as a resistance inductor against leafminer (Liriomysa spp) on two chrysanthemum cultivars. The experiment was carried out in a greenhouse, in Espirito Santo State, Brazil. The experimental design was completely randomized, in split split plot scheme, with five repetitions, being two varieties of chrysanthemum (Puritan and Yellow Diamond) allocated in the plot and in the subplot five doses of basic slag $\left(0.00 ; 1.40 ; 2.80 ; 4.20\right.$ and $\left.5.60 \mathrm{~g} \mathrm{pot}^{-1}\right)$ and in the subsubplot the weeks. The evaluations were carried out weekly, during nine weeks, observing the presence of leafminer and the number of mines in each leaf. The basic slag from metallurgy showed to be potential against the leafminer. The two chrysanthemum cultivars also showed differences in susceptibility to leafminer attack.
\end{abstract}

Keywords: Liriomyza spp., Dendranthema grandiflorum Tzvelev, pest management.

(Recebido para publicação em 20 de abril de 2007; aceito em 11 de abril de 2008)

A floricultura ganha expressão, por sua relevante contribuição tanto econômica como tecnológica, caracterizando-se como uma atividade representativa no agronegócio brasileiro. A cultura do crisântemo (Dendranthema grandiflorum Tzvelev) possui grande importância na floricultura brasileira e seu cultivo tem aumentado em todo país.

O cultivo do crisântemo em vaso ocupa o primeiro lugar no mercado nacional, respondendo por aproximadamente $80 \%$ da produção total. O segundo lugar é ocupado pelo cultivo chamado "de corte" (Fernandes, 1996). Suas flores têm grande aceitação de mercado, sendo por isso considerada uma das plantas ornamentais de maior valor comercial (Mainardi et al., 2004). Entretanto, esta cultura vem se mostrando bastante suscetível ao ataque de insetospraga, e em especial, da mosca minadora (Liriomyza spp Diptera: Agromyziidae). Devido às galerias feitas pelas larvas no mesófilo foliar, a qualidade da planta fica comprometida (Gallo et al., 2002).
No caso da planta cultivada em ambiente protegido, o aparecimento da praga, pode ocorrer em qualquer período, o que aumenta a depreciação do produto.

O controle preventivo é feito através de pulverizações no início da cultura com inseticidas sintéticos, o que aumenta o custo de produção e pode prejudicar a qualidade do meio ambiente e a saúde do produtor e consumidor. Além disso, o uso indiscriminado desses produtos pode levar ao surgimento da resistência a campo. Desta forma, faz-se necessário o estudo de táticas de controle menos agressivas ao meio ambiente e que proporcionem uma elevada produção, viabilizando economicamente e ambientalmente o cultivo do crisântemo.

Nos últimos anos o silício tem despertado a atenção e o interesse de pesquisadores de todo mundo; estudos recentes têm mostrado que o silício pode estimular o crescimento e a produção vegetal por meio de várias ações diretas e indiretas, propiciando proteção contra fatores abióticos, como estresse hídricos, toxidez de alumínio, ferro, entre outros (Adatia \& Besford, 1986), e bióticos, como a incidência de doenças e de insetos-praga (Epstein, 1994). O silício pode promover menor incidência de patógenos e aumento na proteção contra herbívoros, incluindo os insetos fitófagos, por meio da formação de barreiras mecânicas e/ou pela alteração das respostas bioquímicas da planta ao ataque do parasita, aumentando a síntese de toxinas que podem agir como substâncias inibidoras ou repelentes (Dannon \& Wydra, 2004; Epstein, 1994; Marschner, 1988). Blum (1968), analisando a resistência mecânica de plântulas de sorgo à penetração de larvas da mosca Atherigona varia soccata (Rond.) (Díptera: Muscidae), observou que barreiras mecânicas incluem mudanças na anatomia das plantas, como células epidérmicas mais grossas e um grau maior de lignificação e/ou silicificação (acúmulo de silício). A sílica amorfa ao acumular-se nas células da camada epidérmica forma uma 
Tabela 1. Número de larvas vivas (NLV) e número de folhas minadas (NFM) por Liriomyza spp em crisântemo (Dendranthema grandiflorum) cultivar Polar Branco e Polar Amarelo durante nove semanas de avaliação ${ }^{(1)}$. Alegre, UFES, 2005.

\begin{tabular}{|c|c|c|c|c|c|c|c|c|c|}
\hline \multirow{2}{*}{ Cultivares } & \multicolumn{9}{|c|}{ Semanas } \\
\hline & $1^{\mathrm{a}}$ & $2^{a}$ & $3^{a}$ & $4^{a}$ & $5^{a}$ & $6^{a}$ & $7^{a}$ & $8^{a}$ & $9^{a}$ \\
\hline P. Branco & $3,56 \pm 1,0 \mathrm{a}$ & $4,48 \pm 0,2 b$ & $5,20 \pm 1,0 \mathrm{~b}$ & $5,48 \pm 0,5 b$ & $5,52 \pm 0,4 b$ & $5,52 \pm 0,7 b$ & $5,52 \pm 0,8 b$ & $5,56 \pm 1,0 \mathrm{~b}$ & $5,56 \pm 1,3 b$ \\
\hline \multirow[t]{3}{*}{ P. Amarelo } & $3,76 \pm 0,9 a$ & $5,72 \pm 0,7 \mathrm{a}$ & $7,88 \pm 0,7 \mathrm{a}$ & $8,76 \pm 1,1 \mathrm{a}$ & $8,96 \pm 0,6 a$ & $9,92 \pm 0,4 \mathrm{a}$ & $9,92 \pm 0,6 \mathrm{a}$ & $10,12 \pm 1,0 \mathrm{a}$ & $10,16 \pm 0,5 a$ \\
\hline & \multicolumn{9}{|c|}{ Semanas } \\
\hline & $1^{\mathrm{a}}$ & $2^{a}$ & $3^{a}$ & $4^{a}$ & $5^{a}$ & $6^{a}$ & $7^{a}$ & $8^{a}$ & $9^{a}$ \\
\hline P. Branco & $0,64 \pm 0,2 b$ & $0,00 a$ & $0,40 \pm 0,1 \mathrm{~b}$ & $0,80 \pm 0,3 a$ & $0,00 \mathrm{a}$ & $0,40 \pm 0,4 a$ & $0,00 \mathrm{a}$ & $0,00 \mathrm{a}$ & $0,00 \mathrm{a}$ \\
\hline P. Amarelo & $1,24 \pm 0,3 \quad a$ & $0,00 \mathrm{a}$ & $0,84 \pm 0,2 a$ & $0,20 \pm 0,1 \mathrm{a}$ & $0,00 \mathrm{a}$ & $0,00 \mathrm{a}$ & $0,00 \mathrm{a}$ & $0,00 a$ & $0,00 \mathrm{a}$ \\
\hline
\end{tabular}

(1) Médias seguidas pela mesma letra na coluna não diferem entre si ao nível de $5 \%$ de probabilidade pelo Teste "t".

barreira física estável à penetração de alguns tipos de fungos e ao ataque de insetos-praga. Neste aspecto, o papel do silício incorporado à parede celular torna-se semelhante ao da lignina, que é um componente estrutural resistente à compressão. Dessa forma, a aplicação de silício na cultura do crisântemo poderá elevar o grau de resistência das plantas e consequentemente, reduzir a infestação e os prejuízos causados por Liriomysa spp.

Entre os produtos utilizados com maior frequiência como fontes de silício na agricultura estão os silicatos de potássio, produtos especialmente desenvolvidos para aplicações foliares e as escórias siderúrgicas, que são aplicadas ao solo e adicionam significativas quantidades de silício ao solo entre outros nutrientes.

Assim, as perspectivas de utilização da escória siderúrgica no manejo de insetos-praga são ótimas devido ao baixo custo, facilidade de adoção e compatibilidade desta tática com outros métodos de controle, contribuindo para uma produção voltada ao contexto da agricultura sustentável. Este trabalho objetivou o uso de um composto silicatado (escória siderúrgica) como forma de induzir a resistência ao ataque da mosca minadora (Liriomyza spp) em duas cultivares de crisântemo.

\section{MATERIAL E MÉTODOS}

A pesquisa foi desenvolvida no $\mathrm{Mu}-$ nicípio de Iúna (ES), em estufas plásticas, utilizando-se vasos de 1,3 L, preenchidos com substrato (solo + composto orgânico + areia), aplicando-se como fonte de silício, uma escória siderúrgica, silicato de cálcio e magnésio em pó
(23\% $\mathrm{SiO}_{2}, 36 \% \mathrm{CaO}$ e $6 \% \mathrm{MgO}$ ) nas doses: $1=0$ (sem aplicação de escória); $2=1,40 \mathrm{~g}$ de escória por vaso; $3=2,80$ $\mathrm{g}$ de escória por vaso; $4=4,20 \mathrm{~g}$ de escória por vaso e $5=5,60 \mathrm{~g}$ de escória por vaso, incorporadas ao substrato antes do plantio procedendo-se a incubação dos vasos durante 30 dias. Após o período de incubação foi feita à leitura do $\mathrm{pH}$ em água $(1: 2,5)$ do substrato dos vasos. Os tratamentos, com cinco repetições, foram dispostos em delineamento inteiramente casualizado, em esquema de parcelas subsubdivididas, onde as cultivares compreenderam a parcela, as doses a subparcela e as semanas a subsubparcela, totalizando 50 unidades experimentais. Foram utilizadas as cultivares Puritan ("Polar Branco") e Yellow Diamond ("Polar Amarelo"), adquiridas da Holambra.

As plantas foram propagadas por estaquia e tratadas com $1000 \mathrm{mg} \mathrm{L}^{-1}$ de ácido indol-butírico. As estacas foram colocadas nos vasos com os diferentes tratamentos e mantidas por três semanas em estufa de enraizamento. Em cada vaso foram colocadas seis estacas. Decorridas as três semanas, os vasos foram transferidos para as estufas de produção, onde foram repicadas, regulando a altura das plantas, induzindo a brotação lateral. A adubação foi realizada na forma de fertirrigação, utilizando como fonte de nutrientes o nitrato de amônio, MAP e nitrato de potássio, na formulação 25-05-20 (\% N-P-K).

Os tratos culturais (desbrota, uso de reguladores de crescimento e manejo da fertirrigação) foram os mesmos adotados no cultivo comercial da empresa, com exceção apenas do controle da praga. Aplicou-se semanalmente o silicato de potássio (via foliar), na do- sagem de $4 \mathrm{~g} \mathrm{~L}^{-1}$ para todos os tratamentos, com exceção apenas do tratamento que recebeu a dose 1 de escória. A aplicação de silicato de potássio é uma forma de aumentar a chance de formação de uma barreira física estável, uma vez que não se sabe se o crisântemo é uma planta acumuladora de silício e, portanto, a aplicação foliar aumenta as chances de absorção e polimerização do silício na epiderme foliar.

As avaliações do número de folhas minadas e do número de larvas vivas de Liriomyza spp foram realizadas semanalmente, durante nove semanas. Os dados foram submetidos à análise de regressão linear e análise de variância, e as médias comparadas pelo Teste de " $t$ ", a $5 \%$ de probabilidade.

\section{RESULTADOS E DISCUSSÃO}

Houve diferença entre as cultivares de crisântemo quanto ao número de folhas minadas (NFM) e o número de larvas vivas (NLV). A cultivar Polar Branco foi a que apresentou menor suscetibilidade ao ataque da mosca minadora, verificando-se menor NFM e NLV ao longo do período de avaliação (Tabela 1). Essa maior resistência e/ou tolerância apresentada pela cultivar Polar Branco pode ser atribuída provavelmente a fatores genéticos, uma vez que as cultivares receberam tratamentos iguais e obtiveram respostas diferentes. Deren et al. (1992) afirmam que as plantas diferem bastante na sua capacidade de absorver o silício, com o envolvimento de genes aditivos ou não aditivos no mecanismo de absorção do silício, como é o caso do arroz. Assim, até mesmo genótipos de uma mesma espécie podem apresentar concentrações 


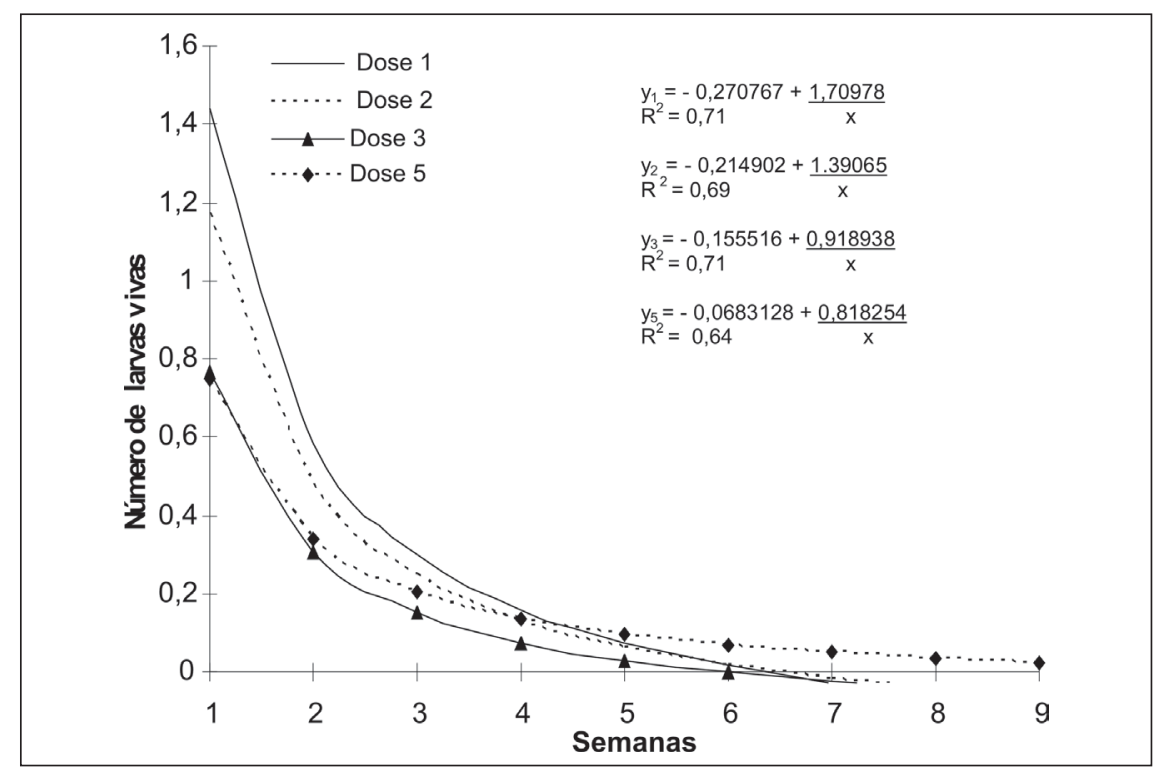

Figura 1. Número de larvas vivas (NLV) de mosca minadora (Liriomyza spp) em folhas de crisântemo (Dendranthema grandiflorum Tzvelev) em função da época de avaliação e das diferentes doses de escória. Alegre, UFES, 2005.

variadas de silício, respondendo de modo distinto à aplicação do elemento (Winslow, 1992). Dessa forma, mesmo sendo geneticamente controladas, a resistência e a tolerância podem ser bastante influenciadas por fatores nutricionais da planta, e neste caso, o envolvimento do silício parece ter um papel importante nas relações plantaambiente.

Não foi observado efeito significativo das doses da escória aplicadas, bem como da interação doses x cultivares, doses $\mathrm{x}$ semanas na redução do número de folhas minadas. Contudo, verificouse efeito significativo para doses de escória, com referência ao NLV após nove semanas de avaliação, não sendo possível obter o ajuste da equação de regressão para a dose de escória de 4,20 g por vaso (Figura 1). A dose de escória de $2,80 \mathrm{~g}$ por vaso foi a que promoveu maior redução do número de larvas vivas encontradas ao longo das nove semanas. Resultados semelhantes foram observados por Parrella et al. (2006) usando aplicações foliares de silicato de potássio. De acordo com esse trabalho a adição de $200 \mathrm{mg} \mathrm{L}^{-1}$ de silicato de potássio em plantas de crisântemo teve efeito significativo na redução do número de larvas vivas de mosca minadora em relação à testemunha avaliadas ao longo de seis semanas, com correlação negativa entre doses de silício e NLV.
Os mesmos autores descrevem que foram observados maiores teores de silício acumulado nas folhas do crisântemo quando se aplicou maiores doses de silicato de potássio, porém este não reduziu significativamente o NLV. Winslow (1992) e Deren et al. (1994) descrevem que o acúmulo de Si possivelmente contribui para a resistência às doenças e insetos , embora, nem sempre plantas com altos conteúdos de $\mathrm{Si}$ acumulados apresentem resistência. Fatores físicos, bioquímicos, além da genética, podem também influenciar a resistência a insetos e esses devem ser identificados (Savant et al., 1997). A maior dose (5,60 g por vaso) apresentou desempenho inferior à dose de 2,80 g por vaso, provavelmente devido à elevação do $\mathrm{pH}$ do substrato, o qual atingiu valores de 7,8. Segundo Korndorfer (2007), as escórias, além de serem as principais fontes de silício para o solo, são também utilizadas como corretivos da acidez, isto é, têm a capacidade de neutralizar a acidez do solo e produzir o ácido monossilícico $\left(\mathrm{H}_{4} \mathrm{SiO}_{4}\right)$, que é a principal forma de silício absorvido pelas plantas. Assim, a sua aplicação e sua respectiva dissolução eleva o $\mathrm{pH}$ do solo e os teores de cálcio e magnésio, permitindo além da reposição destas bases no complexo de troca, a neutralização do alumínio trocável. Com o aumento do $\mathrm{pH}$, a atividade de silício em solução tende a aumentar. No entanto a atividade do cálcio em solução tende a diminuir (Lindsay, 2001), podendo influenciar na disponibilidade de cálcio para as plantas e seu fluxo para o citoplasma. Isto poderá afetar a estabilidade das biomembranas, alterando a resistência da parede celular (Taíz \& Zeiger, 2004). Como o cálcio, o magnésio e os micronutrientes podem também diminuir suas atividades com o aumento do $\mathrm{pH}$, que por sua vez pode influenciar na biossíntese da clorofila, já que esses nutrientes funcionam como constituintes de estruturas orgânicas, predominantemente envolvidas na função catalítica de enzimas (Taíz \& Zeiger, 2004). Dessa forma, a falta ou excesso de um ou mais destes nutrientes influencia não só o crescimento e a produtividade, mas também pode afetar a resistência ou a tolerância da planta a doenças e pragas.

Ressalta-se que os trabalhos que abordam o efeito do silício no manejo de insetos são escassos (Korndorfer et al., 2004; Moraes et al., 2005), mas mostram que o silício pode vir a ser um importante instrumento do manejo de pragas, permitindo a substituição e/ou a redução do uso de agrotóxicos convencionais.

\section{REFERÊNCIAS}

ADATIA MH; BESFORD AT. 1986. The effects of silicon on cucumber plants grown in recirculating nutrient solution. Annual Botanical 58 343-351.

BLUM A. 1968. Anatomical phenomena in seedlings of sorghum varieties resistant to the sorghum shoot fly Atherigona varia soccata. Crop Science 8: 388-391.

EPSTEIN E. 1994. The anomaly of silicon in plant biology. Proceeding of the National Academic of Science 9: 11-17.

DANNON EA; WYDRA K. 2004. Interaction between silicon amendment, bacterial wilt development and phenotype of Ralstonia solanacearum in tomato genotypes. Physiological and Molecular Plant Pathology 64: 233-243.

DEREN CW; DATNOFF LE; SNYDER GH. 1992. Variable silicon content of rice cultivars grown on Everglades Histosols. Journal of Plant Nutrition 15: 2363-2368.

DEREN CW; DATNOFF LE; SNYDER GH; MARTIN FG. 1994. Silicon concentration, disease response and yield components of rice genotypes grown on flooded organic Histosols. Crop Science 34: 733-737.

FERNANDES ALT. 1996. Monitoramento da cultura do crisântemo em estufa através do uso de lisímetro e estação agrometeorológica automatizados. Piracicaba: USP-ESALQ, 96p (Tese mestrado). 
GALLO, D. 2002. Entomologia Agrícola. Piracicaba: FEALQ, 920p.

KORNDORFER GH; PEREIRA HS. 2001. O papel do silício na citricultura. Revista Citricultura Atual 4: 16-18.

KORNDORFER AP; CHERRY R; NAGATA R. 2004. Effect of calcium silicate on feeding and development of tropical sod webworms (Lepidoptera: Pyralidae). Florida Entomologis, 87: 393-395.

KORNDORFER GH. 2007. Uso do silício na agricultura. Informações Agronômicas, Piracicaba, p. 9-11. International Plant Nutrition Institute, n. 117.

LINDSAY WL. 2001. Chemical equilibria in soils. New Jersey: Blackburn. 449p.
MAINARDI JCT; BELLÉ RA; MAINARDI L. 2004. Produção de crisântemo (Dendranthema grandiflorum Tzvelev.) "Snowdon" em vaso II: ciclo da cultivar, comprimento, largura e área foliar. Ciência Rural 34: 1709-1714.

MARSCHNER H. 1988. Mineral nutrition of higher plantas. 2nd ed. London: Academic Press. 740p.

MORAES JC; GOUSSAIN MM; CARVALHO GA; COSTA RR. 2005. Feeding nonpreference of the corn leaf aphid Rhopalosiphum maidis (Fitch, 1956) (Hemiptera: Aphididae) to corn plants (Zea mays L.) treated with silicon. Ciência Agrotécnica 29: 761-766.
PARRELLA MP; COSTAMAGNA T; KASPI R. 2006. The addition of potassium silicate to the fertilizer mix to suppress Liriomyza leafminers attacking chrysanthemums. Bulletin Gerbera Pest Management Alliance 29: 159-162.

SAVANT NK; SNYDER GH; DATNOFF LE. 1997. Silicon management and sustainable rice production. Advances in Agronomy 58: 151199.

TAIZ L; ZEIGER E. 2004. Fisiologia vegetal. Porto Alegre: Artmed. 719p.

WINSLOW MD. 1992. Silicon, disease resistance and yield of rice genotypes under upland cultural conditions. Crop Science 32: 12081213. 